\title{
Estágios da Licenciatura em Gestão e Desenvolvimento Social
}

Num contexto de profunda mudança e de necessária inovação, torna-se um imperativo a cooperação das instituições de ensino superior com as empresas e com todas as organizações responsáveis pelo desenvolvimento.

Esta necessidade não tem sido vista de igual modo pelas diferentes partes. Verifica-se no ensino superior a consciência da importância do "interface" com a vida económica em geral. Mas, sobretudo relativamente à indústria, continua a verificar-se um certo nível de descrença e de cepticismo sobre o papel e o valor do ensino superior.

A função principal do ensino superior, que é a de promover o avanço do conhecimento através do ensino e da investigação, é de crucial importância para permitir que as organizações assegurem o seu sucesso e/ou lucro através dos seus produtos ou serviços.

A promoção de estágios nas organizações, pelo ensino superior, pode ser um caminho a seguir no estabelecimento de estruturas para o diálogo.

As organizações têm, assim, uma forma de acesso privilegiado a um potencial recrutamento de alta qualidade, bem como a oportunidade para influenciar o conteúdo e a qualidade dos programas de ensino superior no médio e longo prazo.

O ensino superior pode sentir mais de perto o "feedback" dos programas de estudo, relativamente aos requisitos das organizações, assim como o seu contributo para o aperfeiçoamento continuado dos referidos programas, de modo a proporcionar "curricula" de alta qualidade e a reforçar as perspectivas de emprego dos licenciados.

As organizações económicas começam a ter cada vez mais consciência de uma responsabilidade social mais vasta em relação à educação em geral.

A gestão do interface entre o ensino superior e as organizações é vital. É uma responsabilidade que deve ser especificamente conferida ao mais alto nível de decisão das organizações.

A integração de estagiários nas organizações sociais e económicas tem sido uma das preocupações do Instituto Universitário de Desenvolvimento e Promoção Social (I.U.D.P.S.). Neste Instituto Universitário é ministrado o curso de Licenciatura em Gestão e Desenvolvimento Social, cujo plano de estudos comporta um estágio curricular no $5 .^{\circ} \mathrm{e}$ último ano do curso.

A criação da Licenciatura em Gestão e Desenvolvimento Social resultou de uma proposta feita à Universidade Católica Portuguesa, por um grupo de representantes de empresas, de autarquias, de instituições privadas de solidariedade social e de investigadores, atentos à realidade sócio-económica da região.

Tendo a preocupação de manter uma forte ligação com os agentes económicos e sociais, considerando as exigências de formação teórica e prática e a disponibilidade de recursos humanos existentes, foram seleccionadas, como áreas de inter- 
venção para os estagiários da Licenciatura, as áreas de Gestão Geral, Gestão de Recursos Humanos e Desenvolvimento Social.

Com este estágio pretende-se articular, o mais possível, formação teórica e formação prática, através da indispensável ligação entre as instituições de ensino superior e as organizações sociais e económicas. Constitui um meio adequado, para que os objectivos da Licenciatura em Gestão e Desenvolvimento Social sejam atingidos.

O esforço de gestão do estágio integrado na Licenciatura, levado a cabo pelo I.U.D.P.S., tem sido conseguido, graças à colaboração de todos os docentes, ao corpo de supervisores e aos responsáveis pela gestão das organizações económicas e sociais. Estes não só permitiram a integração do(s) aluno(s) como também desenpenharam um papel fundamental na orientação dos seus trabalhos, em articulação com o supervisor de cada estagiário.

No ano lectivo 1990/91 realizaram estágio os primeiros 67 alunos do $5 .^{\circ}$ ano da Licenciatura em Gestão e Desenvolvimento Social.

Para o efeito contou-se com a colaboração de 56 organizações económicas e sociais, que disponibilizaram 74 lugares de estágio.

\section{Gráfico I}

Centros de estágio no ano lectivo 1990/91

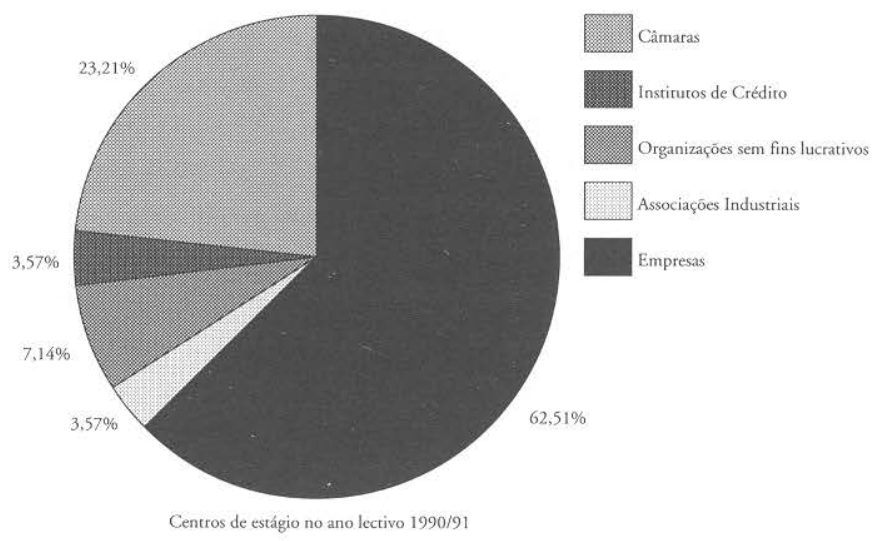

Fonte: Dados do processo de estágios do ano lectivo 1990/91

Pela análise do Gráfico I, podemos verificar que $62.51 \%$ das organizações que colaboraram na integração dos estagiários eram empresas, 3.57\% associações industriais, $7.14 \%$ organizações sem fins lucrativos, $3.57 \%$ eram instituições de 144 crédito e as restantes $23.21 \%$ câmaras. 
Gráfico II

Localização dos centros de estágio do ano lectivo 1990/91

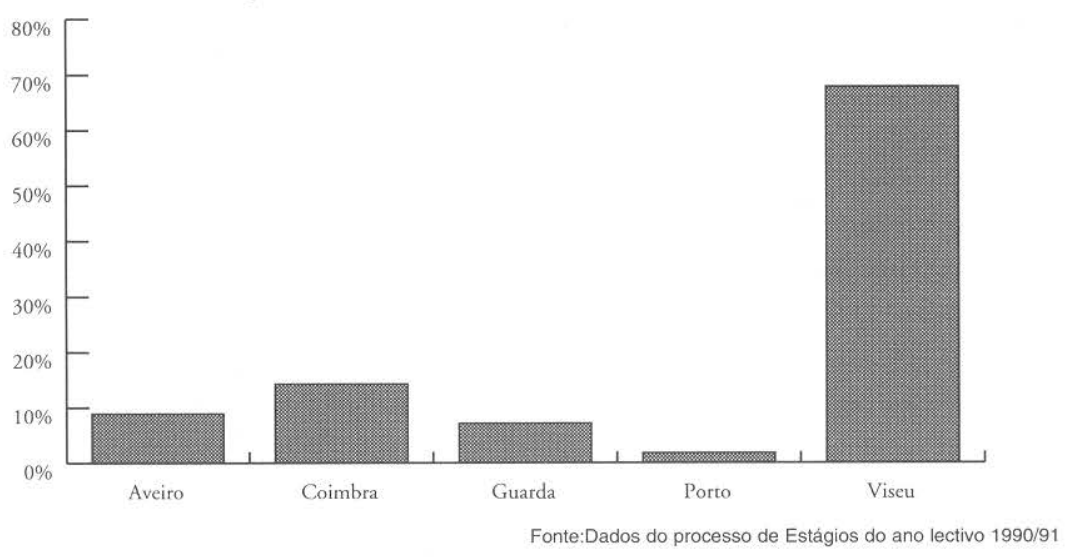

Tal como podemos verificar pela análise do Gráfico II, nem todos os centros de estágio se localizam no Distrito de Viseu.

Neste ano lectivo disponibilizaram lugares de estágio organizações económicas e sociais localizadas nos Distritos de Aveiro (8.93\%), Coimbra (14.29\%), Guarda (7.14\%), Porto (1.79\%) e Viseu (67.86\%).

No ano lectivo 1991/92 realizaram estágio 67 alunos.

Contou-se com a colaboração de 74 organizações económicas e sociais que disponibilizaram 91 lugares de estágio.

Gráfico III

\section{Centros de estágio no ano lectivo 1991/92}

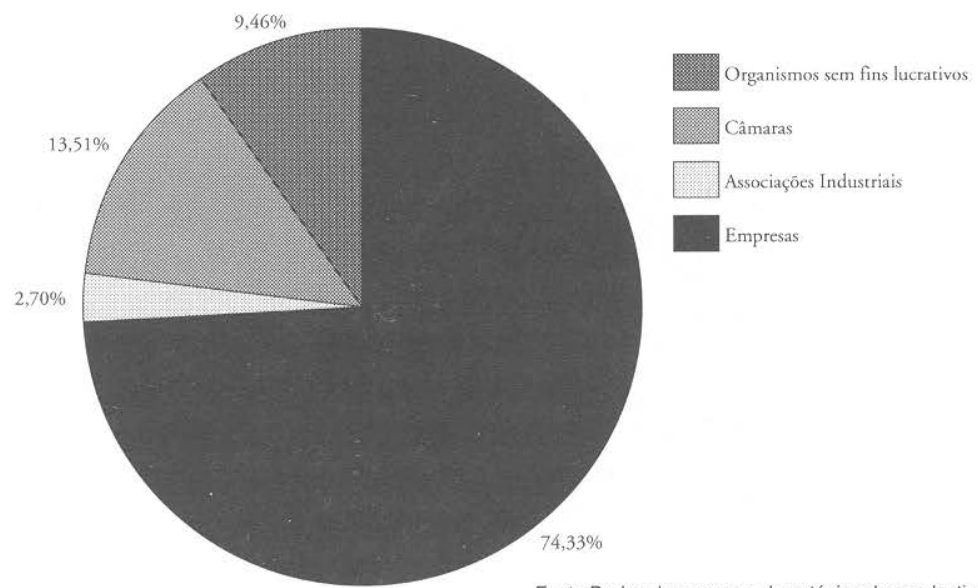


Das organizações que colaboraram no processo de estágios, para este ano lectivo, $74.33 \%$ eram empresas, $2.70 \%$ associações industriais, $13.51 \%$ câmaras e $9.46 \%$ organizações sem fins lucrativos.

\section{Gráfico IV}

Localização dos centros de estágio do ano lectivo 1991/92

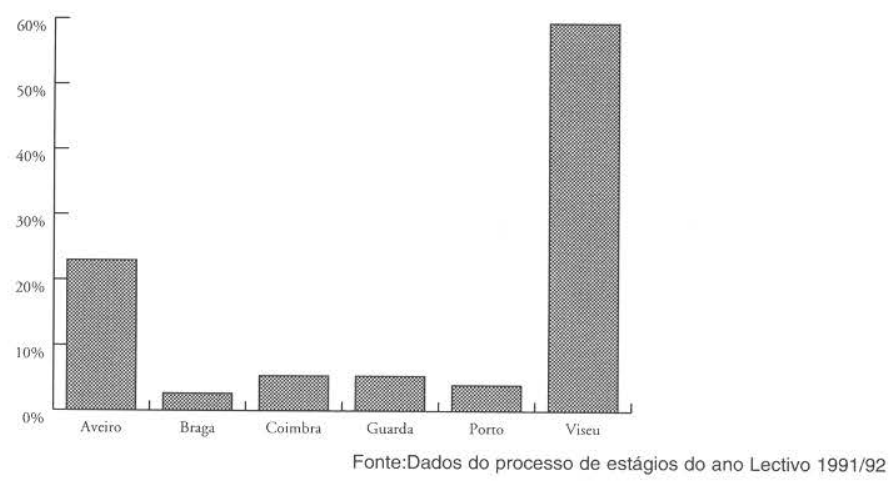

Neste ano lectivo os alunos ficaram distribuídos por 6 Distritos. Das organizações que disponibilizaram lugares de estágio, $22.97 \%$ pertenciam ao Distrito de Aveiro, $2.70 \%$ ao de Braga, $5.41 \%$ ao de Coimbra, $5.41 \%$ ao da Guarda, $4.05 \%$ ao Distrito do Porto e $59.46 \%$ ao de Viseu.

No ano Lectivo 1992/93 realizaram estágio 51 alunos.

Contou-se com a colaboração de 60 organizações económicas e sociais que disponibilizaram 72 lugares de estágio.

\section{Gráfico V}

Centros de estágio no ano lectivo 1992/93

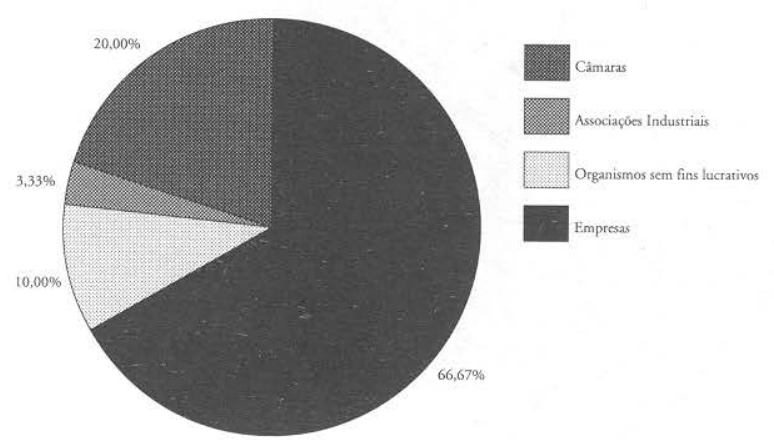


Das 60 organizações que colaboraram para o desenvolvimento do processo de estágio, $66.67 \%$ eram empresas, $10.00 \%$ organizações sem fins lucrativos, $3.33 \%$ associações industriais e $20.00 \%$ câmaras.

\section{Gráfico VI}

Localização dos centros de estágio do ano lectivo 92/93

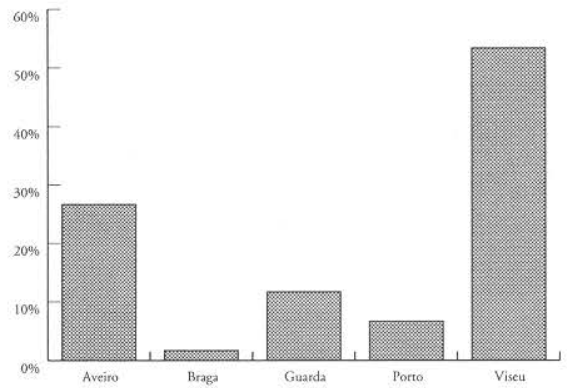

Fonte:Dados do processo de estágios do ano lectivo 1992/93

As organizações, tal como se pode verificar pelo Gráfico VI, estão distribuídas pelos Distritos de Aveiro (26.67\%), Braga (1.67\%), Guarda (11.67\%), Porto $(6.67 \%)$ e Viseu $(53.33 \%)$.

O processo de integração dos alunos estagiários nas organizações, para o ano Lectivo 1993/94, está já a decorrer.

Escolheram lugar de estágio 73 alunos, que vão frequentar o $5 .^{\circ}$ ano da Licenciatura em Gestão e Desenvolvimento Social, no dito ano lectivo.

Contou-se, para o efeito, com a colaboração de 83 organizações económicas e sociais, que disponibilizaram 104 lugares de estágio.

Gráfico VII

Centros de estágio para o ano lectivo 1993/94

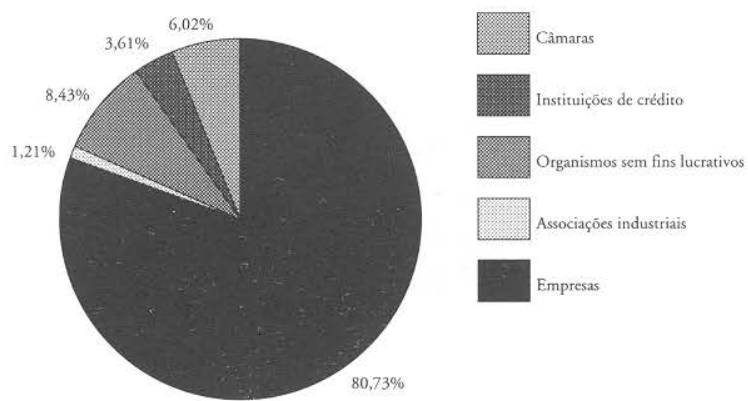


Tal como se pode verificar pelo Gráfico VII, destas organizações, $80.73 \%$ são empresas, $8.43 \%$ organizações sem fins lucrativos, $1.21 \%$ associações industriais, $3.61 \%$ instituições de crédito e $6.02 \%$ câmaras.

Neste ano lectivo os centros de estágio distribuem-se por mais Distritos, alguns dos quais mais afastados do I.U.D.P.S..

Gráfico VIII

Localização dos centros de estágio do ano lectivo 1993/94

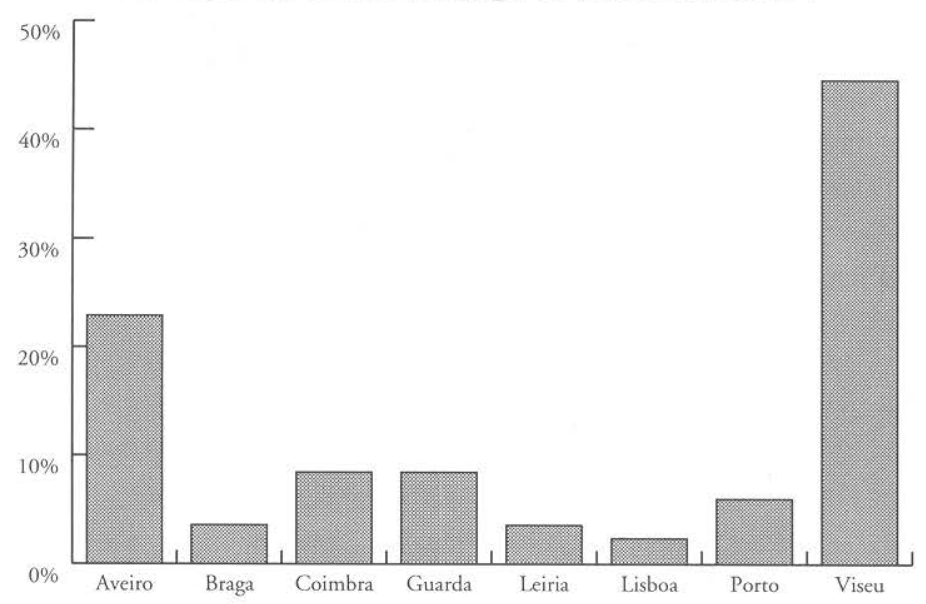

Fonte: Dados do processo de estágios do ano lectivo 1993/94

Assim, podemos verificar que $22.89 \%$ das organizações que disponibilizaram lugares de estágio estão localizadas no Distrito de Aveiro, 3.61\% no de Braga, $8.43 \%$ no de Coimbra, $8.44 \%$ no da Guarda, $3.61 \%$ no de Leiria, $2.41 \%$ no de Lisboa, $6.02 \%$ no do Porto e $44.58 \%$ no de Viseu.

Podemos concluir que são sobretudo empresas industriais que colaboram com o I.U.D.P.S., para proporcionarem aos estagiários contacto com a realidade profissional, onde futuramente se irão inserir.

A maior parte das organizações localizam-se nos Distritos de Viseu e Aveiro, estando a verificar-se um alargamento a outros Distritos, mais distantes da tradicional área de influência do I.U.D.P.S..

O estágio anual termina com a apresentação pública, perante um júri, do relatório elaborado pelo aluno, em função do trabalho realizado. 